\title{
Does rural primary care ophthalmology teaching need revisiting?
}

\author{
Chirag Patel ${ }^{1}$
}

Received: 8 February 2020 / Revised: 27 February 2020 / Accepted: 28 February 2020 / Published online: 11 March 2020

(c) The Royal College of Ophthalmologists 2020

Recently, I read a reflective piece to the Editor of the Eye on the undergraduate view of ophthalmology teaching in the UK [1]. This was an article that struck a chord with me, especially since I read medicine at the same University as the author. Reading this article, it appears that not much has changed in undergraduate ophthalmology training since I finished my undergraduate medical degree. For me, Ophthalmology was not delivered to the level that would prepare me for clinical practice. This problem has been talked about for decades now [2,3]. Nevertheless, the issue remains.

One of the striking things for me, while I went through my junior doctor years, was how unprepared I was for ophthalmology in clinical practice. I spent 2 years doing various terms in general medicine, surgery, paediatrics and emergency medicine. I can remember how difficult I found ophthalmology presentations, and when it came down to referring a patient to an ophthalmology trainee, I was left a little clueless on crucial features of the patient presentation, that I was supposed to elicit and describe as well as examination findings.

Having settled in Australia and completed my rural primary care training, I pondered on my experiences through my journey in medicine and evaluated my post-graduate training without close access to specialist care, such as ophthalmology.

It is well known the population is ageing, which only means an increased incidence and prevalence in eye disease [4]. The potential increase in demand for eye services in rural Australia is daunting [4]. Despite the number of ophthalmology presentations that are seen in primary care [5], I only ever received a 3-h module to work through in my 4 years of primary care training. At no point did an

Chirag Patel

chiragpatel@yourclinicaljourney.com.au

1 College of Medicine and Public Health, Flinders University, Sturt Road, Bedford Park, SA 5042, Australia
Ophthalmologist provide any form of teaching. It puzzled me that for a speciality requiring the acquisition of basic ophthalmology history taking and examination skills, that minimal education was provided. A core skill such as fundoscopy is not taught well in undergraduate medicine. Unfortunately, this theme continues within primary care, where fundoscopy and slit-lamp examination, skills which are potentially sight and lifesaving aren't given the time and day to be taught to trainees. I felt underprepared and inadequate when it came to eye-related problems. I felt out of my depth, more so than with other areas of medicine. This was a common theme in previous studies $[5,6]$.

One of the barriers to learning core ophthalmology skills in Australia is the availability of ophthalmology rotations for primary care trainees. You can argue that the need for providing rural primary care ophthalmology training exists and is beneficial for patients given the inequality of optical services rurally [4]. Why then isn't there a push for rural primary care trainees to be involved in ophthalmology training within the hospital system? Would it not be fair to provide clinic-based ophthalmology rotations to rural primary care trainees, given the need and demand?

Pedagogy in medicine is continually changing and utilising new concepts to aid learning in ophthalmology is vital. Simulation, virtual reality and use of video technology are key areas that should be tapped into. Combining this with Ophthalmologist teaching and skill learning ideally in a clinic setting will go a long way to improve both undergraduate and post-graduate skills.

Ophthalmology teaching begins in undergraduate medicine, and my opinion is that core skills such as fundoscopy and slit-lamp examination should be placed in the same bracket as auscultating and palpating the abdomen i.e. skills that are taught through medical school and enhanced in post-graduate training, such as in rural primary care. Is it now time to think about changing how ophthalmology is delivered to rural primary care trainees and will the colleges work together to achieve this? 


\section{Compliance with ethical standards}

Conflict of interest The author declares that he has no conflict of interest.

Publisher's note Springer Nature remains neutral with regard to jurisdictional claims in published maps and institutional affiliations.

\section{References}

1. Rehan S. The junior doctor view of undergraduate ophthalmology education. Eye. 2018;32:1008-9.
2. Ah-Kee EY, Khan AA. How can undergraduate ophthalmology teaching be improved? Adv Med Educ Pract. 2015;6:469-70.

3. Zhang HH, Hepschke JL, Shulruf B, Francis IC, Spencer SK, Coroneo M, et al. Sharpening the focus on ophthalmology teaching: perceptions of medical students and junior medical officers. Clin Exp Ophthalmol. 2018;46:984-93.

4. Saliba AJ. Impact of rurality on optical health: review of the literature and relevant Australian Bureau of Statistics data. Rural Remote Health. 2008;8:1056.

5. Teo MAL. Improving acute eye consultations in general practice: a practical approach. BMJ Qual Improvement Rep. 2014;3:u206617. w2852

6. Morgan S, Tapley A, Henderson KM, Spike NA, McArthur LA, Stewart R, et al. Australian general practice trainees' exposure to ophthalmic problems and implications for training: a crosssectional analysis. J Prim Health Care. 2016;8:295-302. 